\title{
Fatty acid profiling in gobhi sarson (Brassica napus)
}

\section{Sunidhi Tiwari $凶$}

Department of Genetics \& Plant Breeding, CSK HPKV Palampur (H.P.), India.

\section{S. K. Gupta}

Division of Plant Breeding \& Genetics, Sher-e-Kashmir University of Agricultural Sciences and Technology, FOA, Main campus, Chatha, Jammu (J\&K), India.

\section{S. K. Rai}

Division of Plant Breeding \& Genetics, Sher-e-Kashmir University of Agricultural Sciences and Technology, FOA, Main campus, Chatha, Jammu (J\&K), India.

\section{R. G. Upadhyay}

College of Basic Sciences, CSK HPKV, Palampur (H.P.), India.

Jeevanjot Kaur

Department of Genetics \& Plant Breeding, CSK HPKV Palampur (H.P.), India.

\section{Faisal Jameel}

Division of Plant Breeding \& Genetics, Sher-e-Kashmir University of Agricultural Sciences and Technology, FOA, Main campus, Chatha, Jammu (J\&K), India.

\begin{tabular}{|c|c|}
\hline ARTICLE INFO & ABSTRACT \\
\hline $\begin{array}{l}\text { Received : } 15 \text { October } 2021 \\
\text { Revised : } 18 \text { November } 2021 \\
\text { Accepted : } 28 \text { November } 2021\end{array}$ & $\begin{array}{l}\text { An experiment was carried out during } 2017-2018 \text { to estimate fatty acids and the } \\
\text { oil content (OC) in fifteen Brassica napus genotypes. The quality parameters of } \\
\text { oil include fatty acids (FA) and the oil content (OC), important trait differed } \\
\text { significantly ( } \leq \leq 0.05 \text { ) amongst the Brassica species genotype. Among the } \\
\text { genotypes, significant differences were noted for the fatty acids and the oil } \\
\text { content (OC). In Brassica napus seeds oil content varies in between the range of } \\
37.45-41.86 \% \text { respectively. The saturated fatty acid (SFA) includes the Palmitic } \\
\text { acid (PA) varied in between the range of } 2.68-4.43 \% \text { and oleic acid (OA) } \\
\text { content results lied between } 8.88-56.18 \% \text { respectively. In linoleic acid (LA) and }\end{array}$ \\
\hline $\begin{array}{l}\text { Key Words: } \\
\text { Fatty acids } \\
\text { Brassica napus } \\
\text { Oil content } \\
\text { Quality }\end{array}$ & 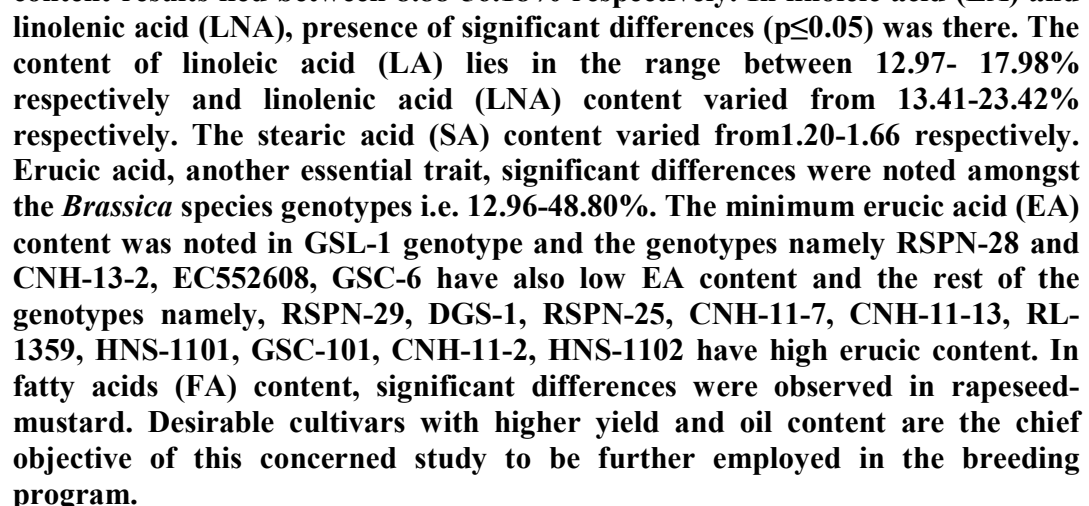 \\
\hline
\end{tabular}

\section{Introduction}

Brassicas mainly comprises various kind of plants, which can be consumed as vegetables, fodder and also a source of oil and spices. The rapeseed mustard, another name of Brassica species is foremost the economically desirable agricultural asset (Chauhan et al., 2020). Area wise, India ranks second and production wise third for oilseed

Brassica crops. Under rapeseed mustard, B. juncea, is grown on more than $80 \%$ of the overall cultivated area in country among the rapeseed mustard group, because it superbly fit in cropping system of rainfed areas. Globally, rapeseed-mustard produce 72.37 million tonnes from a stretch of of 33.64 mha (Anonymous, 2021). India has the

Corresponding author E-mail: sunidhi24tiwari@gmail.com

Doi: https://doi.org/10.36953/ECJ.2021.22347

This work is licensed under Attribution-Non Commercial 4.0 International (CC BY-NC 4.0)

(C) ASEA 
cultivation of rapeseed mustard in an area of 6.23 mha and its production over 9.33 million tonnes and productivity of $15.0 \mathrm{q} / \mathrm{ha}$ during 2018-19 (Anonymous, 2020). During 2017-18, in J\&K state, the rapeseed-mustard crop occupied an expanse of 53000 hectare and have production with 34 thousand quintals and an average productivity with $6.97 \mathrm{q} /$ ha (Anonymous, 2018). In India, for edible oil, the mainly grown oilseed Brassica species are $B$. juncea (Indian mustard), B. napus (gobhi sarson) , B. rapa (turnip) syn. B. campestris and B. carinata (ethiopian mustard) and for seed condiment, $B$. oleracea (brussels sprouts)and $B$. nigra (black mustard) are the main oilseed brassica cultivars are to be cultivated (Jat et al., 2019). Out of these, after oil palm and maize, Brassica napus L. holds the third important place in world among vital oil crops, which has a distinctive record among that crops that are objectives of breeding. The oil extracted from Brassica napus L. are high in quality and rich in fatty acid profiling (Hyder et al., 2021).

Brassica napus (gobhi sarson) has genome AACC with chromosome number $2 \mathrm{n}=38$ which is associated to Cruciferae (mustard) family consist of three thousand other species, and originating when in between Brassica rapa (AA with chromosome number $2 \mathrm{n}=20)$ and Brassica oleracea (CC with chromosome number $2 \mathrm{n}=18$ ), spontaneous hybridization occur (Beszterda et al., 2019).

Fatty acid profiling (also named as FAME) regulates the oil seeds' quality. With the help of identification and quantification in the existing fatty acids in a sample, it helps in processing of the oil. As a result, for the marketplace, fatty acid constitution profile gives critical assistance in evaluating oilseeds and oil which is processed.

Seven major fatty acids appeared from genus Brassica group, mainly, palmitic acid (PA or C16:0), stearic acid (SA or C18:0), oleic acid (OA or C18:1), linoleic acid (LA or C18:2), linolenic acid (LNA or C18:3), eicosanoic acid (C22:0), and lastly, erucic acid (EA or C22:1). As in comparison with other alternative vegetable oils, Brassica oil has greater genetic variations in fatty acids constitution (Sharafi et al., 2015).

The seed oil of Brassica species is specified by notable amount or content of erucic acid i.e. having $50 \%$ of the overall fatty acids (C22:1) and is characterized by a long-chain of monounsaturated fatty acids, primarily not present in any other commercialized plant oil. The oil, higher in erucic acid (EA) can not be utilized for human consumption purpose but have some industrial applications like in printing act as an adhesive, in polyethylene films act as an anti-blocking agents, and in the steel metal industry such as anticorrosive materials. They may also have an application in the fabrication of cosmetics by the incorporation of waxes which can be utilized as a substitute of jojoba oil. Hence there is need to produce varieties having free erucic acid commercially and the varieties which are high in erucic acid for breeding programs and is a propitious objective in brassica oilseed crops. In 1968, the first available cultivar, low in erucic acid (EA) oils were firstly develop in the Brassica napus genotypes is 'Oro' which is agronomically acceptable (Cartea et al., 2019). Apart from these, other promising targets includes expansion of oleic acid (OA) and linoleic acid (LA), and the depletion of linolenic acid (LNA) content (Rebbelen, 1991). As linoleic acid (LA) is useful for nutritional aspect, and in case of oleic acid, thermostability tends to make it useful for oil for cooking purposes. The oil having high oleic acid is better in taste and may also include health benefits. The foremost target of this concerned work to assess the quality of seeds including fatty acid (FA) constitution and seed's oil content (OC)) of genotypes of Brassica napus to find out the qualitatively desirable genotypes, and to evaluate their acceptability for human consumption or industrial applications.

\section{Material and Methods}

The seeds of 15 Brassica napus were procured from various sources (Table 1). Fifteen genotypes of Brassica napus were grown in the experimental field of Division of Plant Breeding and Genetics, Faculty of Agriculture, Sher-e-Kashmir University of Agricultural Sciences and Technology, Jammu (SKUAST, Jammu) during 2017-18. Analyzation of respective dried seed samples was done for oil content (OC) by the use of wide line NMR (New Port Analyzer Model MK III A) and in case of fatty acid constitution by using AIMIL 5700 series gas liquid chromatograph (GLC). Determinations were accomplished as triplicate and then statistically, data were analyzed. 
Table 1: List of Brassica varieties used for evaluation of fatty acid composition and oil content.

\begin{tabular}{|l|l|l|}
\hline S. No & Genotypes & Source \\
\hline 1 & RSPN-29 & SKUAST-J \\
\hline 2 & RSPN-28 & SKUAST-J \\
\hline 3 & DGS-1 & SKUAST-J \\
\hline 4 & RSPN-25 & SKUAST-J \\
\hline 5 & CNH-11-7 & PAU Ludhiana \\
\hline 6 & CNH-11-13 & PAU Ludhiana \\
\hline 7 & GSL-1 & PAU Ludhiana \\
\hline 8 & GSC-101 & PAU Ludhiana \\
\hline 9 & CNH-11-2 & PAU Ludhiana \\
\hline 10 & GSC-6 & PAU Ludhiana \\
\hline 11 & EC552608 & CSKHPKV \\
\hline 12 & CNH-13-2 & PAU Ludhiana \\
\hline 13 & HNS-1102 & CCSHAU \\
\hline 14 & RL-1359 & CSKHPKV \\
\hline 15 & HNS-1101 & CCSHAU \\
\hline
\end{tabular}

\section{Results and Discussion}

The parameters of fifteen Brassica genotypes including total oil content and their range and the mean values is presented in Table 2. Among the genotypes, the seed oil content ranged from 37.45$41.86 \%$ in Brassica napus (Table 2). The results indicates that in between the genotypes of different species, there is presence of variation sufficiently for oil content. In future plant breeding programmes, existence of variation is the astonishing feature of Brassica oil seeds for seed oil content which compel them a potential asset for exploitation. Comparable results have also been shown by Mukherjee and Kiewitt (1984), Rai et al. (2018), Getinet et al. (1997), Rabiee et al. (2004), Wilson (2004), Singh et al. (2014), and Sharafi et al. (2015). These results shows that in plant breeding programmes, the various genotypes can be set out as the pool of qualitative genes which could be utilized for the boosting of oil content (OC) in different species of Brassica genus.

Profiling of fatty acid: The fatty acid (FA) constitution of various Brassica napus genotypes is shown in table 3 . In this concerned study, the saturated fatty acid content i.e. Palmitic acid (PA) varied within the 2.68-4.43\% range in Brassica napus genotypes. Within different Brassica species, the amount of the saturated fatty acid was detected to be below $7 \%$ that is acceptable to be fit for human consumption (Table 3 ). If saturated fatty acids are in higher amounts, Brassica oilseeds prompt to health disorders like in humans such as hypercholesterolemia. On the other hand, species with high palmitic acid will lead to some potential applications such as in industries like chemical and soap related (Singh et al., 2014).

The study of different genotypes of Brassica indicated the enormous differences for the content of unsaturated fatty acids includes the monounsaturated fatty acids (MUFAs), mainly consist of oleic acid (OA), eicosanoic acid, erucic acid (EA), and the polyunsaturated (PUFAs) consist of linolenic acid (LNA) and linoleic acid (LA) respectively. Taking into account this concerned study, the Brassica genotypes showing greater amount of linoleic acids and less amount of erucic acid (EA) could make use in future breeding programs for increasing the quality of oil to be used in industrial and nutritional aspects. Therefore, the foremost promising target in improvement of Brassica programmes implies the decrease in erucic and linolenic acids and rise in oleic and linoleic acids. In case of MUFAs, the oleic acid (OA) content in Brassica napus genotypes varied within 8.88-56.18\% range as shown in Table 3 . Comparable results have also been shown by Rai et al. (2018), Chhokar et al. (2008), Sharafi et al. (2015), and Singh et al. (2014). Oleic acid (OA) has an application in lowering the level of cholesterol, important constituent related to coronary heart disease (Grundy, 1986). Therefore, for human consumption, higher content of oleic acid (OA) is thought to be of having good nutritive utility, as in blood, it enhances the HDL (Highdensity lipoprotein) level and reduces the LDL (low- density lipoprotein) level (Chang and Huang, 1998). Because of increased thermo stability, greater oleic acid content would permit the use of oil more widely (Chauhan et al., 2002). Aside from playing a promising part in enhancing the cooking oil efficiency, oleic acid plays an important role in making the seed's oil much worthy in industrial aspects also (Wilson, 2004). Erucic acid is other desirable MUFA which is reported to be antinutritional factor as high amount of erucic acid is considered to increase blood cholesterol and impair myocardial conductance (Renarid and Mc Gregor 1976). Therefore, it is important to reduce erucic acid up to $2 \%$ (internationally accepted 
Table 2: Total oil content (\%) in various Brassica genotypes

\begin{tabular}{|l|l|l|c|c|c|c|c|c|}
\hline SN & Varieties & $\begin{array}{l}\text { Saturated } \\
\text { Fatty acid } \\
(\%)\end{array}$ & \multicolumn{7}{|l|}{$\begin{array}{l}\text { Unsaturated Fatty acid (\%) } \\
\end{array}$} & & $\begin{array}{c}\text { Palmitic } \\
\text { acid }\end{array}$ & $\begin{array}{c}\text { Oleic } \\
\text { acid }\end{array}$ & $\begin{array}{c}\text { Linoleic } \\
\text { acid }\end{array}$ & Linolenic & $\begin{array}{c}\text { Stearic } \\
\text { acid }\end{array}$ & $\begin{array}{c}\text { Eicosenoic } \\
\text { acid }\end{array}$ & $\begin{array}{c}\text { Erucic } \\
\text { acid }\end{array}$ \\
\hline $\mathbf{1}$ & RSPN-29 & 3.55 & 27.99 & 14.07 & 22.61 & 1.29 & - & 34.56 \\
\hline $\mathbf{2}$ & RSPN-28 & 3.69 & 33.18 & 16.23 & 21.34 & 1.3 & - & 12.96 \\
\hline $\mathbf{3}$ & DGS-1 & 3.55 & 20.71 & 15.40 & 21.15 & 1.27 & 0.38 & 28.13 \\
\hline $\mathbf{4}$ & RSPN-25 & 3.31 & 25.93 & 13.88 & 20.98 & 1.21 & - & 36.48 \\
\hline $\mathbf{5}$ & CNH-11-7 & 3.41 & 28.55 & 14.28 & 13.41 & 1.32 & 0.39 & 31.44 \\
\hline $\mathbf{6}$ & CNH-11-13 & 3.69 & 34.75 & 15.10 & 17.88 & 1.4 & - & 22.80 \\
\hline $\mathbf{7}$ & CNH-13-2 & 4.43 & 56.03 & 15.66 & 16.5 & 1.34 & - & 12.61 \\
\hline $\mathbf{8}$ & EC552608 & 4.32 & 56.18 & 17.98 & 14.32 & 1.61 & - & 18.15 \\
\hline $\mathbf{9}$ & GSC-6 & 3.81 & 32.16 & 14.04 & 22.26 & 1.475 & 0.35 & 18.15 \\
\hline $\mathbf{1 0}$ & RL1359 & 4.09 & 39.7 & 15.25 & 20.50 & 1.65 & - & 25.60 \\
\hline $\mathbf{1 1}$ & HNS-1101 & 3.46 & 32.06 & 15.25 & 22 & 1.34 & - & 24.54 \\
\hline $\mathbf{1 2}$ & GSC-101 & 2.68 & 8.88 & 17.34 & 19.96 & 1.25 & 0.82 & 48.80 \\
\hline $\mathbf{1 3}$ & CNH-11-2 & 4.09 & 32.31 & 15.27 & 23.42 & 1.32 & 0.42 & 24.26 \\
\hline $\mathbf{1 4}$ & GSL-1 & 3.59 & 33.01 & 14.38 & 20.79 & 1.3 & 0.35 & 33.24 \\
\hline $\mathbf{1 5}$ & HNS-1102 & 3.64 & 29.91 & 12.97 & 20.85 & 1.44 & 0.36 & 25.28 \\
\hline Mean & & 3.68 & 32.75 & 15.14 & 19.86 & 1.36 & 0.43 & 26.46 \\
\hline Range & & $2.68-4.43$ & $8.88-$ & $12.97-$ & $13.41-$ & $1.20-$ & $0.36-0.82$ & $12.96-$ \\
& & & 56.18 & 17.98 & 23.42 & 1.66 & & 48.80 \\
\hline
\end{tabular}

norm) for increasing the level of oleic acid which is a cholesterol reducing fatty acid (Chauhan et al., 2007). The linoleic and linolenic acids comes under the PUFAs. The content of linoleic and linolenic acids lies between from 12.97-17.98\% and 13.41$23.42 \%$ in B. napus respectively (Table 3 ). The results come by in this study are in close agreement with those acquired by Rai et al. (2018), Peiretti and Meineri (2007), Singh et al. (2014), and Sharafi et al. (2015). Linoleic acid (LA) is a crucial fatty acid (FA) which is the base for prostaglandin and also for some other necessary body regulators (Chauhan et al., 2002). But linoleic acid (LA) must be procured from diet as it is not able to synthesize by human body itself. Its been described that the level of high LA in edible oil decreases cholesterol in blood and hampers atherosclerosis (Ghafoorunissa, 1994). While linolenic acid (LNA) is further an important fatty acid (FA), so far in the oil, its existence may results in off flavor and rancidity (Sharafi et al., 2015). Oilseed rape (Brassica napus) has seed lipids typically consist of less proportions (below 3\%) of stearic acid. Stearic acid is mainly used as an agent for emulsifying or as an agent to attain high quality consistency in cosmetic products (Zarhloul et al., 2006). In this concerned study, the amount of stearic acid varied between 1.20-1.66 respectively.

The huge amounts of components which are nutritionally undesired such as erucic acid and glucosinolates are present in the Indian rapeseed and mustard cultivars. Hence, there is a necessity to produce new varieties, having low levels of both erucic acid (EA) and glucosinolates. In the present study, the erucic acid (EA) content varied from $12.96-48.80 \%$ in B. napus varieties (Table 3). Erucic acid (EA) is categorized as a natural toxicant and higher erucic acid (EA) in cooking oil leads to negative effects on health. Its most serious damaging health effects involves accumulation of triacylglycerol in the heart caused by inadequate oxidation. Such myocardial lipidosis may leads to bring down contractility of the heart muscle (Vetter et al., 2020). The data revealed that genotypes i.e. GSL-1, RSPN-28 and CNH-13-2, EC552608, GSC6 are low in erucic acid content and tends to make them suitable for commercialized cultivation and also use these for introduction of traits having low erucic acid into cultivars which are higher yielding. Besides this, genotypes of Brassica napus consisting high erucic acid (EA) have an application in industries (Hristov et al., 2011). 
Table 3. Fatty acid composition of various Brassica varieties.

\begin{tabular}{|c|c|c|}
\hline SN & Variety & Oil Content (\%) \\
\hline 1 & RSPN-29 & 41.73 \\
\hline 2 & RSPN-28 & 41.86 \\
\hline 3 & DGS-1 & 39.31 \\
\hline 4 & RSPN-25 & 39.31 \\
\hline 5 & CNH-11-7 & 40.44 \\
\hline 6 & CNH-11-13 & 39.31 \\
\hline 7 & CNH-13-2 & 39.18 \\
\hline 8 & EC552608 & 37.45 \\
\hline 9 & GSC-6 & 39.82 \\
\hline 10 & RL1359 & 40.32 \\
\hline 11 & HNS-1101 & 39.18 \\
\hline 12 & GSC-101 & 37.69 \\
\hline 13 & $\mathrm{CNH}-11-2$ & 40.07 \\
\hline 14 & GSL-1 & 40.45 \\
\hline \multirow[t]{3}{*}{15} & HNS-1102 & 39.18 \\
\hline & Mean & 39.68 \\
\hline & Range & $37.45-41.86$ \\
\hline
\end{tabular}

Lately, there is an extended demand for high erucic acid (EA) rapeseed with an expanding demand for ecological (biodegradable) and eco-friendly oil products namely, cosmetics, soaps, rubber, pharmaceuticals nylon, biodiesel, lubricants, surfactants (Konkol et al., 2019; Li et al., 2012; Hristov et al., 2011). Before the canola varieties were raised for consumption of human in 1974, Brassica napus genotypes were commonly higher in erucic acid (EA) (Lu et al., 2020). Presently, the development of cultivars which are higher in erucic acid (EA) content is a prime concern in breeding of brassica. In this study, the genotypes RSPN-29, DGS-1, RSPN-25, CNH-11-7, CNH-11-13, RL1359, HNS-1101, GSC-101, CNH-11-2, HNS-1102

\section{References}

Anonymous (2018). Digest of Statistics, Directorate of Economics and Statistics, Planning and Development Department, J\&K. 107-112.

Anonymous (2020). Economic Survey of India 2019-20. Department of Economic Affairs. Economics Division, Government of India, New Delhi.

Anonymous (2021). Directorate of Rapeseed-Mustard Research. Indian Council of Agricultural Research. Accessed on 13-04-2021. https://www.drmr.res.in. have high erucic acid (EA) content. The observation of the information concerned with an appreciable amount of variability in fatty acid content of the diverse brassica species can be further make use in the breeding programmes for the development of genotypes with larger qualitative potential.

\section{Conclusion}

Profiling of fatty acid named as the fatty acid methyl esters (FAME) analysis, is done by plant breeders and various producers for estimating composition of oil and the oilseeds. Profiling of fatty acid permits the rapeseed growers, its handlers, its processors and its oil producers to find out the product's oil composition and to confirm the quality of oil and oilseed as products are switched from producer to end user. The analysis of fatty acids (FA) is done by automated, highly efficient gas chromatography (GC), which gives the uncomplicated and simple results. Plant breeders can do profiling of fatty acid as an analytical tool to find out which lines to proceed further. A FAME test gives a quantitative study of the seed oil constitution with merely a sample taken. As in general, the erucic acid (EA) is the major antinutritional factor in Brassica so it should be present in fewer amounts but nowadays it is needed in high amount also for fulfilling the industrial needs. In this concerned study, GSL-1 is the genotype having minimum erucic acid (EA) content and can be used further in future and the genotypes namely, RSPN-29, DGS-1, RSPN-25, CNH-11-7, CNH-11-13, RL-1359, HNS-1101, GSC-101, CNH-11-2, HNS-1102 have high erucic content so can be used in industrial grounds.

Beszterda, M., \& Nogala-Kałucka, M. (2019). Current research developments on the processing and improvement of the nutritional quality of rapeseed (Brassica napus L.). European Journal of Lipid Science and Technology, 121(5), 1800045.

Cartea, E., Haro-Bailón, D., Padilla, G., Obregón-Cano, S., del Rio-Celestino, M., \& Ordás, A. (2019). Seed oil quality of Brassica napus and Brassica rapa germplasm from Northwestern Spain. Foods, 8(8), 292.

Chang, N. W., \& Huang, P. C. (1998). Effects of the ratio of polyunsaturated and monounsaturated fatty acid to 
saturated fatty acid on rat plasma and liver lipid concentrations. Lipids, 33(5), 481-487.

Chauhan, J. S., Tyagi, M. K., \& Tyagi, P. (2002). Genetic analysis of oleic and linoleic acid content in Indian mustard (Brassica juncea L.). SABRAO Journal of Breeding and Genetics, 34, 73-82.

Chauhan, J. S., Bhadauria, V. P. S., Singh, M., Singh, K. H., \& KUMAR, A. (2007). QualiSy characteristics and their interrelationships in Indian rapeseed-mustard (Brassiea sp) varieties. The Indian Journal of Agricultural Sciences, 77(9).

Chauhan, J., Choudhury, P., Pal, S., \& Singh, K. Analysis of seed chain and its implication in rapeseed-mustard (Brassica spp.) production in India. The Indian Society Of Oilseeds Research, 71.

Chhokar, V. I. N. O. D., Beniwal, V. I. K. A. S., Kumar, A. N. I. L., \& Rana, J. S. (2008). Lipid content and fatty acid composition of mustard (Brassica junceae L.) during seed development. The Asian Journal of Experimental Chemistry, 3(1-2), 6-9.

Getinet, A., Rakow, G., Raney, J. P., \& Downey, R. K. (1997). The inheritance of erucic acid content in Ethiopian mustard. Canadian Journal of Plant Science, 77(1), 33-41.

Grundy, S. M. (1986). Comparison of monounsaturated fatty acids and carbohydrates for lowering plasma cholesterol. New England Journal of Medicine, 314(12), 745-748.

Ghafoorunissa, G. (1994). Dietary fats/oils and heart diseases. Sustainability in oil seeds. Indian Society of Oil Seeds Research, Hyderabad, 486-490.

Hristov, A. N., Domitrovich, C., Wachter, A., Cassidy, T., Lee, C., Shingfield, K. J., ... \& Brown, J. (2011). Effect of replacing solvent-extracted canola meal with high-oil traditional canola, high-oleic acid canola, or high-erucic acid rapeseed meals on rumen fermentation, digestibility, milk production, and milk fatty acid composition in lactating dairy cows. Journal of dairy science, 94(8), 40574074 .

Hyder, A., Iqbal, A. M., Sheikh, F. A., Wani, M. A., Nagoo, S., Khan, M. H., \& Dar, Z. A. (2021). Genetic variability studies for yield and yield attributing traits in Gobhi Sarson (Brassica napus L.) genotypes under temperate ecology of Kashmir. Journal of Oilseed Brassica, 12(1), 44-48.

Jat, R. S., Singh, V. V., Sharma, P., \& Rai, P. K. (2019). Oilseed brassica in India: Demand, supply, policy perspective and future potential. $O C L, 26,8$.

Konkol, D., Szmigiel, I., Domżał-Kędzia, M., Kułażyński, M., Krasowska, A., Opaliński, S., \& Łukaszewicz, M. (2019). Biotransformation of rapeseed meal leading to production of polymers, biosurfactants, and fodder. Bioorganic chemistry, 93, 102865.

Li, X., van Loo, E. N., Gruber, J., Fan, J., Guan, R., Frentzen, M., ... \& Zhu, L. H. (2012). Development of ultra-high erucic acid oil in the industrial oil crop Crambe abyssinica. Plant biotechnology journal, 10(7), 862-870.

Lu, S., Aziz, M., Sturtevant, D., Chapman, K. D., \& Guo, L. (2020). Heterogeneous distribution of erucic acid in Brassica napus seeds. Frontiers in plant science, 10, 1744.

Mukherjee, K. D., \& Kiewitt, I. (1984). Changes in fatty acid composition of lipid classes in developing mustard seed. Phytochemistry, 23(2), 349-352.

Peiretti, P. G., \& Meineri, G. (2007). Fatty acids, chemical composition and organic matter digestibility of seeds and vegetative parts of false flax (Camelina sativa L.) after different lengths of growth. Animal Feed Science and Technology, 133(3-4), 341-350.

Robbelen G. 1991. Rapeseed in a changing world: plant production potential. In: GCIRC (Ed), Proceedings of the 8th International Rapeseed Congress, Saskatoon, Canada, 9-11 July 1991, pp. 29-38, GCIRC, Saskatoon, Canada.

Rabiee, M., Karimi, M. M., \& Safa, F. (2004). Effect of planting dates on grain yield and agronomical characters of rapeseed cultivars as a second crop after rice at Kouchesfahan. Iranian Journal of Agricultural Sciences, 35(1), 177-187.

Rai, G. K., Bagati, S., Rai, P. K., Rai, S. K., \& Singh, M. (2018). Fatty acid profiling in rapeseed mustard (Brassica species). Int. J. Curr. Microbiol. App. Sci, 7(5), 148-157.

Wilson, R. F. (2004). Seed composition. Soybeans: improvement, production, and uses, 16, 621-677.

Sharafi, Y., Majidi, M. M., Goli, S. A. H., \& Rashidi, F. (2015). Oil content and fatty acids composition in Brassica species. International Journal of Food Properties, 18(10), 2145-2154.Singh B.K., Bala M. and Rai P.K. 2014. Fatty acid composition and seed meal characteristics of Brassica and allied genera. National Academy Science Letters, 37(3): 219-226.

Vetter, W., Darwisch, V., \& Lehnert, K. (2020). Erucic acid in Brassicaceae and salmon-An evaluation of the new proposed limits of erucic acid in food. NFS Journal, 19, 915.

Zarhloul, M. K., Stoll, C., Lühs, W., Syring-Ehemann, A., Hausmann, L., Töpfer, R., \& Friedt, W. (2006). Breeding high-stearic oilseed rape (Brassica napus) with high-and low-erucic background using optimised promoter-gene constructs. Molecular breeding, 18(3), 241-251. 